\title{
Manuel Cervera-Marzal
}

Titre de l'article :

Désobéissance civile et libéralisme

Résumé de l'article :

Des citoyens peuvent-ils désobéir à la loi, pourtant issue de la volonté majoritaire et de la décision du Parlement légitimement élu, au seul motif qu'elle leur semble injuste ? Face à la pensée conservatrice, tenante de l'ordre établi et réfractaire à la moindre transgression («mieux vaut une injustice qu'un désordre»), la philosophie libérale contemporaine a fourni une défense de la légitimité démocratique de la désobéissance civile. Cependant, les justifications rawlsienne et habermassienne de la désobéissance civile semblent bien timorées dès qu'on accepte de les comparer à la pensée politique des activistes désobéissants eux-mêmes, à savoir Gandhi, Martin Luther King et Howard Zinn. Cette «pensée désobéissante» méconnue, voire occultée, vient révéler les insuffisances et les présupposés de la conception libérale de la désobéissance civile.

Mots clés :

Désobéissance civile. Démocratie. Libéralisme. John Rawls. Jürgen Habermas.

\section{Abstract :}

Can citizen disobey the law, coming from the will of the majority and the decision of the legitimately elected parliament, merely because it seems to them unjust? Opposing the conservative thought, which defends the establish order et condemns any transgression, contemporary liberal thought provided a defense of the democratic legitimacy of civil disobedience. However, the rawlsian and habermasian justifications of civil disobedience seems very moderated when compared to the political thought of disobedient activists themselves, namely Gandhi, Martin Luther King Jr. and Howard Zinn. This unknown « disobedient thought » reveals the shortcomings and assumptions of the liberal concept of civil disobedience.

Key words :

Civil disobedience. Democracy. Liberalism. John Rawls. Jürgen Habermas. 


\section{Désobéissance civile et libéralisme}

Les contributions universitaires relatives aux fondements éthico-politiques de la désobéissance civile - définie ici comme action politique, publique, collective, illégale et non-violente - suivent de près les remous de l'histoire. Le plus souvent anglophones, mais progressivement traduites en français, ces productions théoriques - principalement des articles ou des chapitres d'ouvrage - donnèrent lieu à cinq vagues, chacune correspondant à un évènement historique spécifique : le procès de Nuremberg, le mouvement des droits civiques, la guerre du Vietnam, l'installation de missiles nucléaires en RFA et les résistances altermondialistes au néolibéralisme. Ces travaux s'inscrivent dans leur grande majorité au sein de la philosophie politique libérale. Pourtant, il serait réducteur de réduire la théorie de la désobéissance civile à cette approche dominante. Sur sa droite comme sur sa gauche, l'interprétation libérale - i.e. celle de Rawls et Habermas - de la désobéissance civile a donné lieu à de sérieuses critiques. On doit à la «pensée conservatrice » d'avoir initié le débat concernant la légitimité démocratique de cette pratique contestataire et, plus encore, on doit à la «pensée désobéissante » de Gandhi et Howard Zinn d'avoir pointé les insuffisances de l'approche libérale.

Que la conception libérale ait été critiquée résulte de l'ambigüité même des rapports qu'entretiennent libéralisme et désobéissance civile. Le récent article d'Archon Fung (2011) est à ce titre exemplaire. Prônant le juste milieu entre une approche excessivement contestataire qui ferait de la révolution la condition de possibilité d'une démocratie globale réellement délibérative et une approche trop consensualiste qui adresse un refus absolu à toute action politique non persuasive, Fung cherche à ménager une place à la désobéissance civile au sein des théories de la démocratie délibérative. La désobéissance civile est alors simultanément présentée comme anti et pro-libérale. Mais cet apparent paradoxe est levé dès l'instant où Fung précise que la désobéissance civile s'oppose à la réalité concrète des régimes libéraux actuels dans l'objectif de faire converger ces régimes vers l'idéal libéral d'une démocratie délibérative. L'antilibéralisme de la désobéissance civile n'est donc que provisoire et pragmatique puisqu'il vise, au fond, à renforcer le libéralisme en réduisant l'écart actuel entre la théorie et la pratique, entre la norme et la réalité des régimes libéraux.

Cette dichotomie entre pratique et idéal normatif résout-elle de manière satisfaisante la question du rapport ambigüe entre libéralisme et désobéissance civile ? La désobéissance civile ne s'en prendrait qu'à la finance internationale et aux politiques économiques néolibérales mais laisserait intact, voire appartiendrait sans le savoir, à la riche tradition philosophique libérale, aujourd'hui incarnée par les théories de la démocratie délibérative et le 
constitutionnalisme $?^{1}$ Contre la pensée conservatrice, tenante de l'ordre et inquisitrice de la moindre transgression, la philosophie libérale constitue-t-elle l'unique manière de légitimer la désobéissance civile ? De sorte que seul un usage modéré et parcimonieux de la désobéissance civile serait acceptable ? C'est du moins ce que semblent prétendre les théoriciens libéraux eux-mêmes, qui prennent un soin méticuleux à préciser que désobéissance civile et révolution sont antithétiques (pour Martin Luther King la seconde était le prolongement logique de la première) et qui insistent avec force sur le fait que la désobéissance civile ne conteste nullement l'Etat de droit puisqu'elle n'enfreint ses lois que pour en renforcer le principe - se trouve alors délégitimée toute forme de désobéissance civile libertaire et radicale telle que pratiquée et théorisée par Gandhi et Howard Zinn. Cet article avance l'idée qu'il existe un second registre de légitimation de la désobéissance civile. De facture anti-libérale, cette «pensée désobéissante 》 - nous la nommerons ainsi - puise ses sources chez Gandhi, Martin Luther King et Howard Zinn.

La pensée désobéissante puise ses racines et se cristallise autour d'une défense radicale du bienfondé de la désobéissance civile en démocratie. D'où notre choix de la nommer « désobéissante ». Ceci étant, loin de se cantonner au problème de la désobéissance, il s'agit d'une pensée globale - l'adjectif anglais « comprehensive » conviendrait mieux que celui français de «global» - s'exprimant sur un large ensemble de problèmes classiques de la théorie politique. Les penseurs désobéissants ont pour spécificité d'être aussi des acteurs. A l'inverse, les théoriciens libéraux de la désobéissance civile sont des universitaires dotés d'une connaissance quasi-exclusivement livresque de la chose. Les penseurs désobéissants ont l'avantage d'avoir pratiqué leur objet, « ils savent de quoi ils parlent », dirait-on en langage courant. Par-delà l'unité idéologique de leurs écrits, ces penseurs-acteurs, ces théoriciens-militants partagent l'expérience carcérale. Thoreau, Gandhi et Martin Luther King - les trois fondateurs de la pensée désobéissante - ont chacun éprouvé les ténèbres de l'ergastule. Des éléments tangibles laissent d'ailleurs à penser que le passage par le cachot ne serait pas étranger à leur radicalisation politique ${ }^{2}$. La «seconde vague » de la pensée désobéissante - à laquelle participent Jean-Marie Muller et Howard Zinn - s'est elle aussi directement impliquée dans des actions désobéissantes $^{3}$. La pensée désobéissante est donc inextricable de la pratique qui lui correspond. Pour autant, tout acteur

1 Pour une analyse des rapports entre démocratie délibérative et action directe (que celle-ci soit violente, comme le sabotage ou certaines manifestations, ou non-violente, comme la désobéissance civile), on se reportera au très instructif dossier « Violence et démocratie délibérative » paru dans le n¹, Vol.7 des Ateliers de l'éthique (2012 : 45140).

2 Thoreau rédige La désobéissance civile au lendemain de son incarcération pour refus de payer l'impôt. Gandhi découvre l'opuscule de Thoreau et les textes de Tolstoï - qui auront une influence déterminante sur sa mise en œuvre de la désobéissance civile de masse - lors d'un séjour en prison. Et la radicalisation politique de King se cristallise lors de son séjour dans la prison de Birmingham, d'où il rédigera sur des morceaux de papier toilettes sa fameuse Lettre de la prison de Birmingham.

3 Sans vouloir entrer dans des considérations théoriques trop abstraites à propos du rapport entre la pratique et la théorie, il est évident que, dans le cas qui nous occupe, nous sommes en présence de militants qui, pour mieux cerner les soubassements stratégiques et philosophiques de leurs actes, ont consacré une partie de leur temps au travail intellectuel. Il ne s'agit surement pas d'universitaires qui, voulant confronter leurs théories à la réalité des faits, seraient entrés en désobéissance. Preuve en est que le jeune Martin Luther King se voyait déjà offrir des postes d'enseignant dans les plus grandes universités américaines lorsque, frappé par l'horreur de l'injustice raciale, il décida de se vouer à l'action militante, au prix d'une potentielle grande carrière de théologien. 
désobéissant n'adhère pas nécessairement à la « pensée désobéissante ». Que recouvre-t-elle exactement?

Nous pouvons définir la pensée désobéissante comme «(1) une philosophie politique critique se cristallisant autour de (2) la question de la désobéissance civile, ayant en ligne de mire (3) l'utopie d'une société débarrassée de la violence et (4) ayant la non-violence pour principe d'intelligibilité des phénomènes politiques ». Cette définition comporte ainsi quatre éléments. Partant d'une critique de la philosophie politique classique, la pensée désobéissante aboutit à une philosophie politique critique ${ }^{4}$. La cristallisation de la pensée désobéissante autour du problème de la désobéissance civile est une évidence tant la place de la désobéissance est centrale dans les écrits et la biographie des penseurs appartenant à cette tradition. L'utopie, quant à elle, constitue l'impensé et la ligne de mire de la pensée désobéissante au sens où elle loge en arrière-plan constant de la réflexion, sans jamais apparaître en tant que telle. Elle recèle pourtant de grandes potentialités théoriques qui commencent seulement à être exploitées (Cervera-Marzal, 2012a : 114-138). Grâce à l'utopie - qui par son hyper-positivité vient combler la négativité de la non-violence et de la désobéissance - la pensée désobéissante ne se réduit pas à une philosophie négative. La pensée désobéissante doit donc sa consistance philosophique à l'utopie. Enfin, la non-violence constitue le principe d'intelligibilité politique de la pensée désobéissante au sens où l'on considère généralement que la pensée de Claude Lefort pour principe d'intelligibilité la notion de « conflit », celle de Rancière la notion de « mésentente » ou celle de Castoriadis la notion de « significations imaginaires sociales ». La pensée désobéissante est une philosophie politique de la non-violence.

Selon la pensée désobéissante, que nous ne pouvons pas présenter plus en détails dans le cadre restreint d'un article scientifique ${ }^{5}$, la philosophie libérale - mue par la même crainte du désordre qui conduit les conservateurs à rejeter toute désobéissance - justifie le principe de la désobéissance civile mais en condamne l'usage. Si elle est possible théoriquement, elle n'est pas souhaitable politiquement. Les libéraux fournissent ainsi une défense timorée de la désobéissance civile. Ils l'assortissent de telles limitations qu'ils en arrivent presque à la vider de toute portée pratique (Perrouty, 2000 : 71-72). Et ils n'hésitent pas à se retourner parfois contre elle lorsqu'ils affirment, comme Rawls, que l'injustice d'une loi ne suffit pas à justifier qu'on y désobéisse (1987: 251). En résumé, ils conçoivent la désobéissance civile comme un droit que le citoyen doit utiliser avec parcimonie et retenue. La pensée désobéissante considère à l'inverse, à l'instar de Henry David Thoreau, que la désobéissance est un devoir face à toute injustice, aussi minime soit-

4 Pour comprendre le passage d'une critique de la philosophie politique classique à une philosophie politique critique, il convient de se reporter aux écrits de Miguel Abensour sur le sujet (notamment 2002 : 207-258). Par ailleurs, loin d'être évident, le rapport d'Abensour à la non-violence existe pourtant. Il est médiatisé par sa lecture minutieuse d'auteurs comme Emmanuel Lévinas et Hannah Arendt.

5 Un ouvrage à paraître en septembre 2013 aux Editions des Forges de Vulvain (Désobéir en démocratie) revient de manière plus approfondie sur le substrat de cette «pensée désobéissante », présentée brièvement dans le cadre de cet article. Dans ce livre, nous montrons que la pensée désobéissante s'enracine dans une tradition philosophique profonde et ancienne, qu'elle continue de se manifester sous des formes modernes, partiellement renouvelées, mais foncièrement fidèles au socle théorique initial ; la difficulté étant que les penseurs qui défendent et les activistes qui mettent en œuvre ces idées ignorent souvent leur généalogie commune. L'ouvrage cherche à montrer qu'il est possible et nécessaire, derrière l'éclatement des projets et des idées désobéissantes, d'en retrouver les grandes lignes unificatrices. 
elle (1994). On ne saurait trop désobéir, puisque la désobéissance civile est constitutive de la démocratie. La vertu cardinale du citoyen n'est plus l'obéissance mais la responsabilité. Cette responsabilité autorise à transgresser toute loi injuste $^{6}$, car l'injustice d'une loi n'a de réalité qu'à partir de l'instant où les sujets lui obéissent. La pensée désobéissante et le libéralisme constituent donc deux univers intellectuels incompatibles.

La mise en évidence de l'unité théorique et de la continuité historique de la pensée désobéissante ne constitue pas l'objectif de cet article. Nous ne mentionnons l'existence de cette tradition de pensée méconnue, voire occultée, qu'en raison du soupçon qu'elle vient jeter sur la prétendue affinité élective - qui pour beaucoup a aujourd'hui valeur d'évidence - entre philosophie libérale et désobéissance civile. Pensée désobéissante et pensée conservatrice ne seront donc pas étudiées pour elles-mêmes mais viennent à l'appui d'une démonstration visant à rendre compte du caractère ambigüe des rapports entre libéralisme et désobéissance civile. Partant, nous commencerons par examiner les arguments que les conservateurs opposent à la désobéissance civile. Etudiant ensuite la réplique d'Habermas aux conservateurs allemands et la théorie de la justice comme équité de John Rawls, nous verrons comment l'approche libérale procède à l'éloge d'une désobéissance civile modérée et strictement fidèle aux principes de l'Etat de droit. Enfin, en faisant place à la pensée des acteurs désobéissants eux-mêmes (Gandhi, King et Zinn étant étrangement absents des écrits libéraux sur la désobéissance civile), nous mettrons en évidence les présupposés et les limites de la conception libérale de la désobéissance civile.

\section{Le conservatisme contre la désobéissance civile}

L'argumentaire conservateur est primordial parce qu'il pose les fondements du débat. La théorie de la désobéissance civile dans son ensemble - conservateurs, libéraux et désobéissants inclus - est une théorie de la légitimité de la désobéissance civile. Aussi est-il nécessaire de partir des objections à son bienfondé en démocratie.

Avant de présenter ces objections, précisons le sens donné ici à la notion de «pensée conservatrice ». Cette pensée ne se confond pas ici avec l'acception courante qui en est donnée. Dans les dictionnaires de philosophie politique, le conservatisme est généralement assimilé à une triple critique de la modernité : critique du rationalisme (cartésien et kantien) sous prétexte que cette prétention de la Raison moderne à la maitrise de soi et de la nature n'est rien d'autre qu'un orgueil insensé reposant sur l'oubli du fait que l'homme est limité dans ses choix par la soumission à la Providence divine ou à l'héritage des siècles passés ; critique de l'égalitarisme démocratique au motif que la société est par nature hiérarchisée, de sorte que doivent exercer le pouvoir les sages, les savants et les hommes de vertu ; enfin,

6 Mais cette autorisation n'est pas obligation, car l'activiste doit prendre en compte des considérations stratégiques pouvant parfois l'amener à ne pas désobéir à une loi pourtant jugée injuste. 
critique de l'individualisme au nom du principe selon lequel une véritable société n'est pas un agrégat d'individus mis côte à côte, comme tend à l'être la société moderne, mais une communauté, soudée, vivante, organique et solidaire. La pensée conservatrice ainsi définie n'est pas forcément réfractaire à l'usage de moyens d'action illégaux ; en témoigne le simple fait que ce sont de telles idées (notamment la croyance en la valeur sacrée de toute vie humaine, même embryonnaire) qui poussent certains commandos pro-vie à commettre des actions illégales visant à empêcher par la force certaines femmes d'avorter (Venner, 1995).

De manière plus prosaïque, la «pensée conservatrice» désigne dans le cadre de cet article un ensemble d'arguments visant à ôter toute légitimité aux actions de désobéissance civile. Il s'agit moins de la tradition philosophique d'un Léo Strauss, d'un Joseph de Maistre ou d'un Edmund Burke que d'un état d'esprit foncièrement légaliste, d'une mentalité réfractaire aux mises en question de l'ordre établi. Ainsi définie, la pensée conservatrice nous intéresse dans la mesure où elle met en évidence les objections auxquelles libéraux et désobéissants devront répondre en vue de garantir la légitimité démocratique de la désobéissance civile. Examinons ces objections.

Dans un régime manifestement non démocratique où les droits de l'homme, les libertés individuelles et l'égalité des citoyens sont systématiquement bafoués, il semble admis que la désobéissance civile est légitime, et même nécessaire.

La question s'avère autrement plus polémique quand elle concerne la légitimité de la désobéissance civile en démocratie. Des citoyens peuvent-ils désobéir à la loi, pourtant issue de la volonté majoritaire et de la décision du Parlement légitimement élu, au seul motif qu'elle leur semble injuste ? Le philosophe Christian Mellon s'interroge sur le caractère antidémocratique de la désobéissance civile : «lorsque les lois sont votées par une majorité élue sans fraude et sans intimidation, lorsque les politiques sont définies par un gouvernement émanant d'un suffrage universel, peut-on admettre que des citoyens - même avec les motivations éthiques les plus respectables qui soient - organisent des actions illégales en vue de modifier les lois et politiques qu'ils réprouvent?» (1998: 17).Qui plus est, le juge américain Abe Fortas (1968) soulève des questions essentielles, discutées longuement dans un fameux article du le philosophe Hugo Adam Bedau (1991 : 49-67) : A quel titre peut-on désobéir à la loi alors que, en démocratie, d'autres moyens de lutte et d'expression sont disponibles? Pourquoi agir dans l'illégalité lorsque des voies de contestation légales sont mises à disposition des citoyens ? Et, n'est-il pas risqué de laisser chaque citoyen apprécier librement la validité de la loi ? Si chacun se comporte selon ses désirs, cela n'instituera-t-il pas rapidement le désordre dans toute la société ? Et ne suffira-t-il pas qu'un individu ou un groupe juge une loi contraire à ses intérêts pour qu'il revendique le droit de s'y soustraire ? Enfin, peut-on jamais avoir la certitude que la loi que l'on enfreint est réellement injuste ? Les questions précédentes mettent à jour trois inquiétudes - antidémocratisme, illégalisme, anomisme - qui, si elles ne sont pas exclusives à la pensée conservatrice, constituent le terreau de son rejet de la désobéissance civile. 
Cette dernière contrevient tout d'abord à la procédure démocratique en violant le principe de majorité sur lequel elle s'appuie. La démocratie repose sur l'exigence d'obéissance à la loi de la part de chaque citoyen, même quand les politiques mises en œuvre ne lui conviennent pas (Neal, 2001 : 204). Ce devoir d'obéir dérive de la règle de la majorité entre des sujets politiques égaux. Même les citoyens s'étant prononcés contre la loi ou le candidat vainqueur doivent s'y soumettre dans la mesure où la procédure démocratique a été respectée. Refuser cette obéissance revient à demander un pouvoir de veto individuel qui est incompatible avec la reconnaissance de chacun comme un sujet politique égal à ses pairs. Par conséquent, la désobéissance semble injustifiable en termes démocratiques.

En outre, par leur acte, les désobéissants rompent le contrat social qui les lie aux autres membres de la société. De fait, chaque individu choisissant de résider sur le territoire national consent tacitement à bénéficier des droits garantis par l'Etat et à remplir ses devoirs envers la communauté. Désobéir revient à rompre ce pacte. Les conservateurs, en conséquence, exigent non seulement que l'auteur d'un acte de désobéissance civile soit sanctionné pénalement, mais aussi qu'il accepte sa peine et plaide coupable, même s'il se considère moralement ou constitutionnellement innocent (Power, 1970 : 40). Cette acceptation de la peine n'excuse pas l'acte, mais constitue une preuve centrale de la bonne foi du désobéissant et de son absence d'intention révolutionnaire ou criminelle.

Dans une optique conservatrice, la désobéissance civile ne fait pas que contredire la démocratie au sens procédural ; elle en sape aussi la condition de possibilité, à savoir l'existence de lois. En affaiblissant le pouvoir des autorités politiques et en discréditant la législation en vigueur, la désobéissance risque de conduire la société vers l'anomie et le chaos. Or nous savons, depuis Aristote, que sans lois aucune vie sociale n'est possible et, a fortiori, aucune démocratie. L'argument conservateur mobilisé ici relève de la stratégie de la pente glissante : « Que se passerat-il si tout le monde agit ainsi ?» La désobéissance civile ne résiste pas en effet au test kantien de l'universalisation. L'idée se déploie dans deux versions descriptive et normative. La version descriptive soutient que les actions désobéissantes seront imitées par d'autres, favorisant ainsi l'anomisme et le risque d'anarchie. La version normative fait remarquer que si la désobéissance civile est justifiée pour un groupe en particulier, alors elle l'est pour tous les autres, ouvrant ainsi la voie à l'anarchie.

Mais l'argument conservateur par excellence est résumé dans la célèbre formule de Goethe : « J'aime mieux une injustice qu'un désordre ». Autrement dit, la condamnation d'un innocent serait préférable à la mise en question des autorités et, par conséquent, quand bien même on reconnaîtrait l'injustice d'une loi, il faudrait s'y soumettre. Le présupposé implicite étant que le désordre permettrait la réalisation d'une plus grande injustice ${ }^{7}$. Outre qu'il est

7 C'est là l'interprétation classique de cette formule, et c'est le sens qu'elle a chez les penseurs conservateurs qui, à l'instar de Maurice Barrès, accusaient les dreyfusards de semer la pagaille en injuriant l'armée et la patrie. Il faut cependant innocenter Goethe de l'accusation de cynisme qu'on adresse à cette philosophie. Comme l'a montré Robert Legros (2012), la phrase doit être replacée dans son contexte. Goethe a en réalité écrit : «Cela tient finalement à ma nature, je préfère commettre une injustice que de tolérer un désordre ». Tandis qu'à la fin du siège de Mayence (1793) les Français avaient obtenu le droit de quitter la ville sans être inquiétés, la foule tenta de 
dérangeant que ceux qui professent cette foi soient rarement les mêmes qui auront à subir l'injustice, l'argument pose deux problèmes. Il suppose tout d'abord qu'injustice et désordre entretiennent un rapport d'exclusion ; ce qui est loin d'être toujours le cas. Bien souvent, par exemple avec la répression policière d'une manifestation pacifique, désordre et injustice vont de pair. Par ailleurs, la formule de Goethe repose sur un préjugé péjoratif à l'encontre du désordre, qui serait nécessairement mauvais et dangereux. Il est pourtant permis, avec Claude Lefort, d'envisager une réhabilitation politique du désordre en y voyant l'opportunité d'un nouvel ordre, plus juste que l'ancien (1972 : 470-477).

Le philosophe indien Vinit Haksar propose une version plus nuancée de l'argument «goethien ». Partant du postulat que toute désobéissance civile est « erronée », car dangereuse pour les institutions démocratiques, il distingue néanmoins, en s'appuyant sur deux exemples indiens, une désobéissance dont l'erreur serait « raisonnable » (il faudrait alors tolérer) et une désobéissance dont l'erreur serait « fanatique » (les démocrates ne devraient faire preuve d'aucune indulgence envers cette seconde forme) (Haksar, $2003: 408-419)$. Cette distinction interne entre une forme périlleuse et une forme raisonnable de désobéissance civile fait écho à une autre distinction, établie par John Moreall (1976 : $35-44)$, entre une désobéissance coercitive (faisant pression sur l'adversaire) et une désobéissance persuasive (visant à faire changer la mentalité de l'adversaire). Chez ces deux auteurs entre en jeu la difficile question de la définition de la violence, perçue ou réelle, et de son lien à la désobéissance civile. L'insistance sur le caractère violent de ce type d'action est au cœur des stratégies gouvernementales de « criminalisation » de la désobéissance.

Il n'est pas surprenant que les deux arguments de l'antidémocratisme et de l'anomisme se manifestent surtout, plus que chez les universitaires conservateurs, dans le discours des autorités politiques. Le pouvoir est en effet directement visé, sinon menacé, par les actes de désobéissance civile. Aussi réagit-il à cette forme de contestation par une stratégie de criminalisation ${ }^{8}$. En assimilant volontairement les « désobéissants » à des « délinquants » et depuis peu à des « terroristes $»^{9}$, les gouvernements cherchent à discréditer les premiers aux yeux de l'opinion publique ${ }^{10}$. Il devient alors possible de réprimer la désobéissance civile en toute tranquillité, et de traiter les militants politiques sur le même plan que des délinquants de droit commun. Le cas de Jacques Chirac justifiant les quatorze mois de prison de José Bové est illustratif. Le 14 juillet 2003, le président de la République française fit savoir au porte-parole de la Confédération Paysanne que « les militants syndicaux sont des Français comme les autres et ne doivent pas s'imaginer que cette

lyncher un soldat français qu'elle accusait, d'ailleurs à tort, d'avoir incendié le doyenné de la cathédrale. Goethe s'interposa et évita à ce malheureux une mort assurée. Interrogé plus tard sur les motifs de son intervention, il répondit que mieux valait une injustice qu'un désordre. Entendons par là qu'il préférait laisser s'échapper un coupable potentiel (une injustice) que d'accepter qu'il soit livré à une foule en furie (un désordre). Tout suspect est présumé innocent et a droit à un procès équitable. Rien à voir, donc, avec l'acception conservatrice de cette formule.

8 En 1969, Arendt dénonçait déjà « la propension du gouvernement à traiter les protestataires comme des délinquants de droit commun » $(1972: 56)$.

9 En témoigne le néologisme d'« éco-terroristes » inventé en 2002 par le FBI pour désigner - stigmatiser ? - les militants écologistes.

10 Alain Refalo, professeur des écoles, lui-même militant désobéissant, a détaillé la mise en œuvre de cette stratégie dans son article « La criminalisation de la désobéissance civile » (2005). Nous nous inspirons ici de son article. 
vocation leur donne le droit d'enfreindre la loi ». Enfonçant le clou, il ajoutait que la désobéissance civile n'est pas seulement illégale, elle est violente : «Agir de façon brutale, contraire à la loi, et récidiver, ce n'est pas conforme à l'idée que je me fais d'un Etat de droit ». Si nous citons ces mots, c'est qu'ils concentrent en deux phrases la stratégie rhétorique du pouvoir : refus de considérer la dimension politique de l'acte ; négation de son caractère non-violent, puisque illégalisme et violence sont assimilés sans autre forme de procès ; négation du caractère public de la désobéissance. Ces confusions savamment entretenues permettent de conclure à l'identité de la désobéissance civile et de la désobéissance criminelle. Or, précisément, alors que le désobéissant agit dans un objectif politique (améliorer la loi, promouvoir la justice ou rétablir l'État de droit), le délinquant est motivé par son intérêt strictement personnel ; alors que le désobéissant agit sans violence, ce n'est pas le cas des actes criminels ; alors que le désobéissant agit ouvertement, publiquement et assume les conséquences de son acte, le délinquant opère dans l'anonymat et fuit souvent la responsabilité des actes qui lui sont reprochés.

Il va sans dire que les grands médias nationaux accompagnent généralement cette stratégie de criminalisation, qualifiant de « violence », « vandalisme » ou « brutalité » toute action désobéissante qui porterait atteinte à la propriété privée, fut-elle parfaitement pacifique. L'étude d'Alain Refalo (2005) des dépêches AFP concernant le démontage - et non le « saccage », comme cela fut présenté par les journalistes - du Mc Donald de Millau en août 1999 est à ce titre révélatrice. Les juges participent eux aussi du discours de la criminalisation lorsqu'ils occultent le caractère collectif de la désobéissance civile. «En jugeant les personnes individuellement et non pas collectivement, écrit Alain Refalo, ils assimilent le membre du groupe à un délinquant de droit commun qui doit être jugé en dehors de toute considération philosophique et politique ». La critique de la désobéissance civile est donc souvent le produit des autorités judiciaires et du pouvoir étatique qui, sous une forme vulgarisée, réactivent la rhétorique des penseurs conservateurs dans une visée directement politique : criminaliser, délégitimer et réprimer les pratiques désobéissantes. Si ces attaques connurent une certaine vigueur à l'époque du mouvement des droits civiques, elles ne manquèrent pas de susciter des réactions, au premier rang desquelles celles des penseurs libéraux.

\section{John Rawls, éloge d'une désobéissance civile modérée}

L'œuvre de John Rawls fût l'occasion du véritable renouveau d'une discipline alors en déclin, celle de la philosophie politique. La plupart des pays occidentaux assistaient depuis des décennies à la déliquescence de la grande tradition philosophique, progressivement remplacée par la montée du genre concurrent, celui des sciences sociales. Sa Théorie de la justice, publiée en 1971, donna le coup d'envoi d'un important débat qui concerna très rapidement 
l'ensemble des milieux académiques et universitaires américains. L'ouvrage ambitionne entre autres choses de repenser une question classique de la philosophie politique, celle de l'obligation politique. Autrement dit, il tente d'expliquer comment et sous quelles conditions les citoyens sont tenus de respecter les lois promulguées par l'Etat.

Partant du constat que toute société produit des antagonismes inévitables, Rawls essaie de trouver des règles équitables d'organisation de la vie sociale auxquelles tous pourraient adhérer et ainsi se soumettre. Dans la position originelle, les participants choisissent, derrière un voile d'ignorance, les deux principes suivants, appelés à régir une société juste dans laquelle chacun reconnaîtra son devoir naturel d'obéir aux lois :

-le principe d'égale liberté, selon lequel « chaque personne doit avoir un droit égal au système total le plus étendu de libertés de bases égales pour tous, qui soit compatible avec le même système de libertés pour tous » -le principe de différence, selon lequel « les inégalités sociales et économiques doivent être organisées de façon à ce que, à la fois, on puisse raisonnablement s'attendre à ce qu'elles soient à l'avantage de chacun (2a), et à ce qu'elles soient attachées à des positions et des fonctions ouvertes à tous (2b, principe d'égalité des chances)».

\section{Obéissance aux lois injustes et principe de majorité}

C'est dans ce dispositif théorique général que Rawls aborde la question de la désobéissance civile et les deux problèmes qui l'éclairent : celui de l'obéissance aux lois injustes et celui de la soumission au gouvernement de la majorité.

Une organisation sociale dont les institutions politiques sont fondées sur les principes d'égale liberté et de différence constitue une société conforme à l'idée de justice comme équité. En conséquence, explique Rawls dans le sixième chapitre de la Théorie de la justice, ses membres sont soumis à un ensemble d'obligations. La plus importante d'entre elles est le « devoir naturel» de soutenir et renforcer les institutions de ladite société. Si la structure sociale est juste - au maximum possible étant donné le contexte - chacun a le devoir de respecter les décisions prises selon les procédures démocratiques régulières.

Pour restituer la pensée de Rawls il convient de raisonner comme lui « dans le cadre d'une société presque juste ». Le premier problème concerne l'obéissance aux lois injustes. Le philosophe américain admet, à l'instar des jusnaturalistes classiques, que ce que la loi demande et ce que la justice exige sont des choses bien distinctes. Il ne faut pas confondre ces deux types de normes. Mais en vertu de notre obligation de soutenir un système globalement juste nous devons accepter, dans un tel système, d'obéir à des lois injustes. D'ailleurs, précise Rawls, «étant donné ce que sont les hommes », ce devoir interviendra à de nombreuses occasions. Mais il n'est pas absolu, puisqu'il concerne uniquement les lois ne dépassant pas « un certain degré d'injustice ». Le principe de proportionnalité fournira ici des repères pour parvenir à ce qu'il appelle une « position bien pesée ». 
Le second problème est fortement lié au précédent. Il touche à un aspect fondamental du régime démocratique : le gouvernement de la majorité. « Rawls établit qu'une certaine forme de gouvernement par la majorité, évidemment assorti de toute une batterie de conditions relatives au respect de procédures, garantissant les droits de la minorité, etc., est justifiée comme constituant le meilleur moyen disponible pour assurer une législation à la fois juste et efficace » (Quelquejeu, 1998 : 6). Un régime démocratique ne peut pas d'après lui fonctionner autrement. Le gouvernement par la majorité est l'instrument procédural le plus à même de réaliser les deux principes de justice. Pour autant, il serait erroné de dire que ce que veut la majorité est nécessairement juste. Comme l'a révélé sa « querelle de famille » avec Habermas, la démocratie comporte aussi selon une dimension substantielle (Habermas, Rawls, 1997). De sorte qu'il est toujours possible que la volonté majoritaire enfreigne les contraintes constitutionnelles et prenne des décisions bafouant le droit des minorités, la liberté d'expression, de réunion, etc. Dans ce cas, le premier principe de justice est violé. La possibilité est alors ouverte au citoyen responsable de faire respecter la justice en ayant directement recours à une action de désobéissance civile. Les infractions au second principe de justice sont plus difficiles à constater car il s'agit souvent de programmes économiques et sociaux. Rawls conseille donc de laisser aux institutions démocratiques régulières le soin de régler ces questions. En revanche, une violation majeure du premier principe de justice légitime la désobéissance civile.

Notons d'emblée que Stanley Cavell, l'un des principaux opposants américains à la théorie de la justice comme équité, a objecté à Rawls, en s'appuyant sur le perfectionnisme emersonien, le caractère excluant et discriminant de la discussion sur les principes de justice (2009). En effet, si Cavell conçoit lui aussi la démocratie à partir de la voix des citoyens censés y prendre part, il fait remarquer qu'il existe une différence essentielle entre la conversation visant à définir les principes de justice dans la position originelle et les conversations tenus quotidiennement par les individus réels sur le degré de justice de leur société et de leurs institutions. Car dans le premier cas, fait remarquer Sandra Laugier, élève de Cavell et ayant introduit sa pensée dans les débats francophones, «ne peuvent défendre leur revendication que ceux à qui leur consentement a été demandé (et qui peuvent donc à bon droit le retirer) - qui participent à la conversation de la justice» $(2004: 67)$. En outre, la discussion sur l'éthique de la discussion méconnaît, aux yeux des perfectionnistes, la caractère tragique et toujours problématique de l'accord politique. Le fait de participer à la discussion sur la justice ne signifie pas, contrairement à ce que semble penser Rawls, que j'ai donné mon consentement une fois pour toutes, de manière définitive. Celui-ci est toujours conditionnel et rien n'empêche à un individu de le retirer lorsque la dissonance entre sa voix et celle de ses représentants au gouvernement lui apparaît insupportable. En témoigne de manière exemplaire le refus de Thoreau de payer ses impôts au gouvernement 
esclavagiste et belliciste du Massachusetts. La philosophie perfectionniste s'appuie ainsi sur un individualisme radical (le retrait du consentement, fondé sur l'idée émersionnienne de self-reliance, est toujours possible) lui permettant de reprocher à la philosophie rawlsienne son incapacité manifeste à assumer jusqu'au bout les conséquences de sa prémisse individualiste. Comme le rappelle Cavell, il n'existe pas de limites préalables aux revendications acceptables des individus. Il n'y a pas, autrement dit, de «bonnes manières » de revendiquer. Ce perfectionnisme politique présente certes l'avantage d'assumer pleinement qu'un gouvernement n'est légitime qu'à condition que chacun y trouve sa voix (Laugier, 2004: 26). Cependant, il n'est pas certain que l'individualisme radical qui sous-tend cette pensée permette de fonder solidement ce que d'aucuns nomment aujourd'hui le «vivre-ensemble». Car si le consentement de l'individu est à ce point révisable, la possibilité de faire société se trouve à chaque instant menacée.

2) Définir et justifier la désobéissance civile : stabiliser les institutions justes

Avant d'aborder le problème de la justification de la désobéissance civile, Rawls entreprend de la définir « comme un acte public, non violent, décidé en conscience, mais politique, contraire à la loi et accompli le plus souvent pour amener un changement dans la loi ou bien dans la politique du gouvernement. En agissant ainsi, on s'adresse au sens de la justice de la majorité de la communauté et on déclare que, selon une opinion mûrement réfléchie, les principes de coopération sociale entre des êtres libres et égaux ne sont pas actuellement respectés » (1987: 405). Il s'agit donc d'un acte (une situation de fait qui affecte le droit, mais ce n'est pas un droit (Falcon y Tella, 2003 : 136)), qui est illégal (par omission d'un acte obligatoire ou par commission d'un acte interdit), public (parce qu'il se manifeste dans l'espace public et qu'il vise à interpeller l'opinion publique), politique (dans la mesure où il poursuit des fins innovatrices et fait appel à une conception commune de la justice), non-violent (Rawls ne définit pas), collectif et motivé par des principes éthiques. Mais ces sept éléments de définition sont en réalité autant de conditions de validité qui ont été sélectionnées de sorte que, lorsqu'un acte de désobéissance civile ne les remplit pas, il est pour Rawls illégitime. « La définition de la désobéissance civile, commente Chloé Di Cintio, est davantage une limitation qu'une affirmation du droit de désobéir » $(2010: 170)$.

Rappelons encore une fois que la théorie de la justice comme équité s'applique au cas d'« une société presque 
juste, bien ordonnée dans sa plus grande partie, mais où se produisent néanmoins des violations graves de la justice ». Elle s'intéressera donc au «rôle et [à] la justification de la désobéissance civile dans le cadre d'une autorité démocratique légitimement établie» (Rawls, 1987 : 403). Cette théorie ne s'applique ni aux autres formes de gouvernement ni aux autres formes de dissidence et de résistance.

La question de la justification de la désobéissance civile se ramène à une question de conflit des devoirs : quand le devoir d'obéir aux lois de la majorité cesse-t-il d'être une obligation face au droit de défendre ses libertés et au devoir de lutter contre l'injustice ? La formulation même de la question nous enseigne que la désobéissance civile, pour se justifier, doit faire appel à une conception commune de la justice, c'est-à-dire aux principes de justice préalablement adoptés et reconnus par tous. La justification ne doit en aucun cas invoquer les principes d'une moralité personnelle ou d'une doctrine religieuse. Elle doit être fondée sur des intérêts de groupe, non sur ceux d'un individu. Lorsqu'elle considère que les conditions de la libre coopération sont violées, la minorité désobéissante fait appel à la majorité et à son sens de la justice.

Rawls assortit la désobéissance civile de trois autres conditions de légitimité. Il faut tout d'abord que les moyens légaux de remédier à une situation se soient révélés sans effet. Autrement dit, la désobéissance civile ne doit être employée qu'en dernier recours. Mais cette condition nécessaire n'est pas suffisante. Rawls, hanté comme les conservateurs par le spectre de l'anarchie, fait remarquer que la multiplication des actes de désobéissance civile entraîne des désordres considérables qui risquent de nuire au fonctionnement d'une juste constitution. Aussi les minorités opprimées doivent-elles pratiquer la désobéissance avec prudence et retenue et, si possible, coopérer afin de limiter le niveau global de contestation.

Rawls définit ainsi explicitement trois conditions de validité. Pourtant, sans les présenter comme telles, il en ajoute deux autres. Premièrement, la désobéissance civile doit s'effectuer «dans le cadre de la fidélité à la loi ». Contrairement au militant, à l'insurgé ou au révolutionnaire, le désobéissant ne s'oppose pas au système entier mais uniquement à une loi particulière. Son action est motivée par la volonté d'établir ou de rétablir l'Etat de droit. En enfreignant la loi de manière publique et non-violente, il prouve qu'il lui reste fidèle. Et s'il faut choisir, le désobéissant préférera se sacrifier plutôt que risquer de déstabiliser la société. Deuxièmement, toujours dans une perspective de fidélité à la loi et l'Etat de droit, Rawls exige des désobéissants qu'ils assument les conséquences juridiques de leur acte. Ils doivent être prêts à répondre de leur conduite et à en accepter les conséquences légales. Il s'agit par là de prouver au public que le geste était authentique et mûrement réfléchi. C'est aussi un moyen d'insister sur la responsabilité individuelle de chaque citoyen. Cette exigence de soumission à la sanction juridique est ainsi proclamée d'un commun accord par les libéraux et les conservateurs. Nous verrons dans la conclusion de cet article qu'elle a été fortement rejetée par la pensée désobéissante. 
A supposer que ces cinq conditions - appel à une conception commune de la justice, utilisation en dernier recours, retenue dans la pratique, fidélité à la loi et acceptation de la peine - soient remplies, il devient possible d'exercer la désobéissance civile. Quel rôle remplit-elle alors ? Quelle est sa fonction au sein d'un régime démocratique et d'une société presque juste ? Elle a beau être par définition illégale, elle est selon Rawls un « moyen de stabiliser un système constitutionnel » et de le maintenir. Il faut pour cela l'utiliser peu et à bon escient. Aussi longtemps que les cinq conditions sont remplies, elle ne présente pas de menace d'anarchie. Au contraire, elle permet à la démocratie de mieux s'armer contre ses propres dysfonctionnements.

Mais Rawls n'est pas le seul penseur à inscrire la désobéissance civile dans une théorie de l'Etat de droit, de la démocratie délibérative et du constitutionnalisme. Ronald Dworkin (1996 : 133-150), Norberto Bobbio (1999 : 199 213) et Jürgen Habermas procèdent de la même façon. En l'absence de différence majeure dans la structure argumentative de ces quatre auteurs (à propos, évidemment, du seul problème de la désobéissance), il n'est pas nécessaire de revenir sur chacun d'entre eux pour saisir les caractéristiques essentielles de la théorie libérale de la désobéissance civile. Cependant, la réflexion du théoricien de l'agir communicationnel mérite que l'on s'y arrête.

\section{Jürgen Habermas, la désobéissance civile dans et pour l'Etat de droit}

Habermas se situe dans la droite lignée de Rawls puisqu'il pense aussi la désobéissance civile au sein (1) du cadre strict de la structure sociale déjà existante et (2) d'une société presque juste ${ }^{11}$. En outre, pour l'Américain, la désobéissance est légitime lorsqu'elle fait appel au sens commun de la justice ; l'Allemand exige pour sa part qu'elle fasse appel aux principes de la Constitution ; ce qui dans les deux cas revient à exclure la possibilité d'une infraction motivée par des intérêts particuliers. Toute désobéissance n'est pas acceptable car, selon le philosophe allemand, celle-ci n'est civile qu'à condition qu'elle soit issue de la société civile. Par conséquent, les riches ne peuvent se soustraire aux lois organisation la redistribution et les grandes entreprises ne peuvent contourner des mesures visant la protection de l'environnement, « dans la mesure où les acteurs économiques "capitalistes" ont été par avance exclus de la société civile » (Lemasson, 2008 : 60). Enfin, on remarquera qu'Habermas et Rawls s'élèvent tous deux contre le positivisme juridique et légitiment la désobéissance civile par la violation de droits fondamentaux et par la mise en cause de valeurs partagées par l'ensemble des citoyens.

Pourtant, des différences existent. L'ancien philosophe de l'école de Francfort présente une réflexion davantage circonstanciée et moins abstraite que celle de Rawls. Il nourrit ses développements normatifs par des prises de positions

11 Pour une comparaison de leurs théories de la démocratie, on se référera à Catherine Audard (2002 : 95-132). 
sur des cas concrets, tel celui des antimilitaristes allemands des années 1980, et il dénonce la stratégie du pouvoir, des «médias morveux» et des juristes réactionnaires qui cherchent à criminaliser l'action de citoyens engagés. La désobéissance civile est présentée par les professeurs de droit public comme un élément subversif visant l'instauration de la dictature indirecte d'une élite de gauchistes. C'est pour répondre à ces attaques néoconservatrices qu'Habermas engage une réflexion polémique sur ce thème.

La thèse d'Habermas se laisse résumer ainsi : la désobéissance civile, tant qu'elle s'inscrit dans le cadre de l'Etat de droit - c'est-à-dire tant qu'elle fait appel aux principes de la Constitution pour se légitimer et qu'elle demeure nonviolente - constitue un facteur de progrès pour ce même Etat de droit ; thèse à laquelle souscriraient probablement Rawls et nombre de libéraux. Thèse qui, par ailleurs, s'oppose frontalement aux idées conservatrices présentées précédemment. Or, l'intérêt d'Habermas est d'avoir explicitement développé une critique de ce conservatisme, qu'il nomme « hobbisme allemand» et dont il fait remonter les fondements théoriques à Thomas Hobbes et Carl Schmitt (1990: 95-98).

Habermas constate, comme nous l'avions fait plus haut, que les conservateurs se soucient exclusivement de l'ordre, ce au détriment de la justice. Hantés par le spectre de l'anarchie, ils tiennent pour légitime toute forme de domination du moment qu'elle assure de manière effective la paix intérieure. Leur fascination pour la paix juridique les fait passer totalement sous silence l'exigence de légitimation de la force dont l'Etat s'approprie le monopole. Tant qu'elle garantit l'ordre, la légalité ne nécessite aucunement d'être validée par des contenus qui la fasse reconnaître comme juste. Aussi, pour les conservateurs, la loi ne saurait être enfreinte sous aucun prétexte, et ceux qui s'y risquent en faisant acte de désobéissance civile sont automatiquement classés comme « ennemis de l'Etat », au même titre que les terroristes ou les délinquants de droit commun. Cette vision de la chose pose deux graves problèmes. D'abord, en évacuant de la sorte les questions de validité et de légitimité, le hobbisme allemand étouffe toute possibilité de vie citoyenne. La démocratie s'en trouve menacée dans son existence même. Ensuite, le hobbisme, en écartant la question de la légitimation, considère implicitement que le fondement d'un ordre politique réside dans cet ordre lui-même. Or, fait valoir Habermas, la légitimité interne ne suffit pas. L'ordre juridique dans son ensemble doit pouvoir être justifié par des principes qui lui sont extérieurs. La constitution doit ensuite être en accord avec ces principes. En l'absence d'une de ces deux conditions, l'obéissance aux lois ne peut être requise $(1990: 98)$ La voie est alors ouverte à une désobéissance civile légitime. En outre, dans un effort autocritique qu'il convient de saluer, Habermas fait valoir, à l'encontre de sa propre conception procédurale de la démocratie, que la rationalité des normes issues du processus de délibération ne garantit pas mécaniquement leur validité. «Par rapport à une telle procédure reconnue légitime, écrit-il, on peut toujours faire valoir la différence entre un résultat "valide" et un résultat "rationnellement 
acceptable" (dans le cadre institutionnel donné), que ce soit au nom de la réserve exprimée par une minorité qui se contente de se soumettre à des décisions irréprochables du point de vue procédural, ou au nom d'une protestation symbolique » $(1997: 410)$.

Par ailleurs, en ne prenant en compte que le souci de la paix juridique, les conservateurs adoptent une vision erronée de ce qui fait l'essence de l'Etat de droit. Ce dernier repose non sur un mais sur deux principes constitutifs, pourtant antagoniques : la garantie de la paix intérieure et l'exigence que l'ordre de l'Etat soit reconnu par les citoyens comme légitime, et ce de leur propre chef, c'est-à-dire délibérément. Ces deux idées entrent en tension au moment d'aborder la question de l'obéissance au droit. De la première - la seule que Hobbes prenne en compte - il s'ensuit que l'on exige d'obéir aux lois inconditionnellement, de la deuxième il s'ensuit au contraire qu'il faille obéir en connaissance de cause. La désobéissance civile, en mettant à l'épreuve l'Etat de droit, permet d'évaluer sa maturité à travers sa capacité à concilier ces deux exigences contradictoires.

La démocratie doit donc saisir la désobéissance civile comme une « chance » dont elle peut «tirer du positif» (1990 : 88). Elle permet de tester la «maturité » de l'Etat de droit en évaluant sa capacité à concilier les deux exigences contradictoires susmentionnées : la préservation de la paix sociale et la production de légitimité du système. Ainsi, une constitution démocratique tolère la dissidence sous réserve que ceux qui la mettent en œuvre justifient leur action par une invocation crédible des principes de la Constitution, et en l'exerçant sans violence (Habermas, 2003 : 155). En tolérant une désobéissance ainsi conditionnée, l'Etat de droit fait preuve de sa souplesse et de sa capacité d'adaptation. Il protège la démocratie en garantissant un retour réflexif sur sa propre normativité. Cependant, s'il convient d'accorder aux dissidents une marge de manœuvre, celle-ci doit être pondérée et mise en tension avec le souci symétrique de préserver la stabilité des institutions démocratiques. Pour prévenir une extension généralisée ou injustifiée des pratiques illégales, Habermas conditionne la désobéissance civile au respect du principe d'ultime recours. Le désobéissant ne peut entrer en action qu'après avoir épuisé sans succès «toutes les possibilités formelles de révision » (Habermas, 1998 : $322)$.

En outre, la désobéissance civile constitue une garantie du lien social (Ferrarese, $2010: 201-202)$. Elle permet de « tenir ensemble » la communauté. La conception d'Habermas s'écarte notoirement de celle d'Hannah Arendt (1972). Cette dernière, dans sa présentation de la tradition américaine de l'« association », fait de la désobéissance une rupture légitime d'un contrat social toujours révisable (dans sa forme horizontale). «Chez Habermas, loin de rompre un contrat social, le geste de désobéissance civile le réaffirme ». En reconnaissant la légitimité de la désobéissance civile, l'Etat fait œuvre de tolérance vis-à-vis des dissidents. Mais cette tolérance n'a rien de gratuit. Elle repose sur le pari que « ces derniers, qui pourraient en fin de compte se révéler 
être des ennemis de la Constitution, ont tout de même une chance de se présenter, en dépit des apparences, comme les vrais patriotes de la Constitution qu'ils prétendent être » (Habermas, 2003 : 156). En qualifiant de «politique » ce refus d'obéissance qui pourrait bien ne pas l'être, Habermas rend possible un nouveau débat d'interprétation de l'ordre constitutionnel. La désobéissance civile n'est donc qu'un prolongement - sous forme d'action protestataire - de la logique vertueuse de l'agir communicationnel.

Ceci étant dit, Habermas assortit la désobéissance d'un ensemble de conditions de validité similaires à celles déjà mentionnées par Rawls : respect de l'ordre juridique dans son ensemble, volonté d'assumer les conséquences pénales de son acte, utilisation en dernier recours et légitimation de l'acte à partir de la Constitution. Ainsi les Etats et les régimes libéraux doivent être contestés au nom de leurs propres principes, car la tension est purement interne entre les idéaux qu'ils proclament et la réalité des dispositifs de pouvoir. L'idéal normatif libéral constitue l'horizon politique indépassable, de sorte que la désobéissance civile ne saurait s'y opposer.

Le normativisme de la théorie habermassienne de la désobéissance civile fait à la fois sa force et sa faiblesse. Sa faiblesse tout d'abord. Pour Habermas, la pensée politique critique doit être liée de manière dialectique à un compte-rendu sociologique des injustices et des conflits de la vie sociale. Pourtant, malgré cette louable déclaration d'intention, dans la pratique sa théorie ne se conforme pas à cette exigence. Sa théorie politique normative et celle de Rawls ont été sévèrement critiquées pour l'inadéquation de leurs affirmations sociologiques. Loïc Mc Nay n'hésite pas à écrire que leurs théories se basent sur « une abstraction intenable vis-à-vis de la réalité sociologique ». (2008 : 87). La question de l'effectivité de la démocratie est à ce titre exemplaire. Habermas qualifie l'Etat de droit de processus pas encore «arrivé à son terme». Or, comme le fait remarquer Yves Sintomer, contrairement à ce que postule Habermas, ce n'est pas simplement que la concrétisation de l'Etat de droit démocratique soit nécessairement inachevée : cet idéal est défiguré par des rapports de domination contingents. « La police en est sans doute l'incarnation la plus symbolique : nécessaire pour réprimer les violences «privées » et protéger les plus faibles, elle tente en même 
temps d'imposer le respect d'un ordre globalement injuste » (Sintomer, 1999 : 332). Par ailleurs, la désobéissance civile met en évidence la difficulté inhérente à toute théorie politique normative. Si elle se cantonne au devoir-être, elle risque de n'être valable que pour une société d'anges. Si, à l'inverse, elle prétend décrire le fonctionnement «réel» de la société sans prendre au sérieux les recherches en sciences sociales, elle risque de projeter le normatif sur le descriptif et de délivrer une analyse biaisée du social. Aussi, conclut Sintomer, une «bonne » théorie de la démocratie et de la désobéissance civile doit être étroitement couplée avec une théorie de l'injustice et de la domination.

Cependant, le normativisme habermassien fait aussi la force de sa théorie. Tout un pan de la pensée critique ne s'est jamais émancipé du vieux mythe de l'extinction du politique. La prévision marxiste de l'avènement du communisme donna naissance à l'image d'une société transparente à elle-même. Tragique par ses effets, la prophétie saint-simonienne croyait pouvoir annoncer le passage prochain du gouvernement à l'administration des choses. De cette utopie d'une société réconciliée s'ensuit généralement qu'en son sein la désobéissance civile et toute autre forme de contestation n'ont plus droit de cité. Rawls et Habermas rejettent à raison ce fantasme totalitaire de la disparition du conflit. Pour eux, même dans une société utopique - société «presque juste »ou «à peu près démocratique » - la désobéissance civile reste légitime et bénéfique à la vie politique.

\section{Désobéissance civile radicale et risque d'anomie}

Face au discours des gouvernements et de la frange conservatrice des intellectuels, se dressent les universitaires libéraux. La désobéissance civile apparaît dès lors comme un concept libéral. Le souci pour l'individu, la méfiance envers l'Etat et la référence commune au droit naturel expliquent cette appartenance apparente. Mais on constate un écart entre la justification constitutionnaliste-libérale de la désobéissance civile et le discours des acteurs, bien plus radical, mais moins audible. Un détour par la pensée désobéissante de Gandhi, Martin Luther et Howard 
Zinn - tous trois incarcérés à plusieurs reprises pour avoir enfreint la loi de manière politique, publique et non-violente - est susceptible de révéler la dimension légaliste et le présupposé antianarchique12 de la conception libérale de la désobéissance civile.

\section{1) Désobéissance civile modérée et radicale}

Le premier et principal reproche s'adresse à l'opération de domestication que le libéralisme fait subir à la désobéissance civile. En affirmant que la désobéissance est par définition respectueuse des principes de l'Etat de droit, c'est-à-dire modérée, les libéraux commettent une double négation historique et philosophique. Au niveau historique, une telle définition minimaliste de la désobéissance civile aboutit à exclure de cette catégorie un ensemble de phénomènes qui en font pourtant bien parti et qui se revendiquent de cette notion : occupations de logements vides, reprise de terres agricoles et plus généralement toute action illégale et non-violente qui ne viserait pas seulement la modification d'une loi mais le renversement de l'ordre juridico-politique libéral. Au niveau philosophique, la définition libérale repose sur l'illusion que seule l'invocation des droits de la personne ou de la Constitution serait de nature à justifier l'infraction au principe de majorité, refermant ainsi toute possibilité de penser la démocratie au-delà de sa forme libérale et représentative. La pensée désobéissante ne reproduit pas l'erreur de la pensée libérale, qui consisterait à inverser naïvement la proposition et à affirmer que toute désobéissance civile est radicale ou anarchique. De manière plus nuancée, Gandhi et ses successeurs mettent en évidence l'existence de deux formes de désobéissance civile, l'une modérée, l'autre radicale, l'une réformiste, l'autre révolutionnaire, et reprochent ainsi aux théoriciens libéraux d'avoir occulté la seconde en réduisant la désobéissance civile à sa manifestation réformiste.

Dans leur ouvrage sur La production de l'idéologie dominante, Luc Boltanski et Pierre Bourdieu rappellent à juste titre que les penseurs qui ne reconnaissent « la pensée conservatrice que

12 Sans confondre « anarchique » et « anarchiste ». Le premier adjectif renvoie à la notion de désordre et le second à une idéologie politique qui, loin de promouvoir le désordre, adopte se donne comme slogan et comme objectif « L'ordre moins le pouvoir ». 
dans sa forme réactionnaire, celle-là même que le conservatisme est le premier à combattre », sont toujours « en retard d'une guerre » (2008). Gandhi approuverait ce rapprochement à peine voilé du libéralisme au conservatisme puisqu'il construit sa pensée sur une opposition frontale au libéralisme sous toutes ses formes - économique, politique et philosophique (Pantham, 1983 : 165-188; Cervera-Marzal, 2012b : 125-141). Le philosophe français gandhien Jean-Marie Muller (1994 et 1997) n'est pas plus tendre lorsqu'il dénonce les «nombreux libéraux, qui sont prêts à dénoncer l'injustice et à la combattre par les moyens constitutionnels, [mais] n'accepteront pas de franchir le seuil qui les ferait entrer dans l'illégalité. Pour eux, l'ordre est indivisible et toute désobéissance ne peut être qu'un facteur de désordre. [...] L'homme libéral, en effet, souhaite que les opprimés puissent obtenir la reconnaissance de leurs droits, mais il possède une patience et un optimisme qui lui permettent d'attendre et de faire confiance aux pouvoirs établis. Aussi juge-t-il les méthodes d'action directe, et notamment les actions de désobéissance civile, comme des actes extrémistes et peu raisonnables » (Muller, $1981: 77)$.

Mais ce jugement n'est-il pas excessif dès lors que Rawls et Habermas ont tous deux légitimé l'usage de la désobéissance civile en démocratie ? Non, répondent les penseurs désobéissants. Car, comme le fait remarquer Pierre-Arnaud Perrouty, «Rawls se montre très prudent sur la question de la désobéissance civile. S'il semble en approuver le principe, [...] il l'assortit d'une telle série de conditions et de limites qu'il en arrive presque à la vider de toute portée pratique » (2000 : 71-72). De même pour Habermas qui fait en réalité l'éloge d'une résistance modérée, tellement limitée qu'elle en vient au final à n'être légitime que dans un faible nombre de cas. Une analyse serrée du texte Rawls suffit à montrer que s'il justifie le principe de la désobéissance civile, il en verrouille fermement l'usage. La désobéissance est possible théoriquement, mais indésirable politiquement. Elle n'est d'après lui jamais indispensable, ni même nécessaire (Di Cintio, 2010 : 153). L'auteur de la Théorie de la Justice prend le contrepied de Gandhi - pour qui l'injustice d'une loi exige qu'on y désobéisse - lorsqu'il affirme, au contraire, que «l'injustice d'une loi n'est pas, en général, une raison suffisante pour ne pas y obéir » (1987 : 
251). Ainsi, alors que Martin Luther King et Howard Zinn insistent sur l'existence d'une dimension insurrectionnelle de la « civilité », Rawls attribue à ce terme un sens parfaitement opposé. Le « devoir naturel de civilité » revient d'après lui à accepter les défauts des institutions démocratiques (Di Cintio, 2010 : 153). Notons d'ailleurs que l'injonction à obéir aux lois injustes n'est pas chez Rawls un hapax. Elle constitue le postulat de base, le fondement premier de la théorie rawlsienne de la désobéissance civile, et cette injonction est reformulée par l'auteur à de nombreuses reprises. En outre, une lecture d'inspiration straussienne du paragraphe 57 de La théorie de la justice suggère que la pensée de Rawls puisse être contraire à l'enseignement exotérique transmis dans le livre. Étant donné l'intitulé du paragraphe - «La justification de la désobéissance civile»- le lecteur s'attend à y trouver une réponse à la question « pourquoi la désobéissance civile est-elle légitime ? » Or, bien au contraire, Rawls entreprend de répondre à une toute autre interrogation : «à quelle condition la désobéissance civile n'est-elle pas illégitime ?» Ce glissement de l'affirmation à la double négation n'est pas un détail rhétorique insignifiant. Car, en abordant le problème de cette manière, Rawls, au lieu de fournir de «bonnes raisons de désobéir », élabore toute une série de conditions limitant les cas dans lesquels la désobéissance civile sera jugée légitime. Nous présentions plus haut Rawls comme le défenseur de la désobéissance civile contre les attaques conservatrices. Mais, aux vues de ce qui vient d'être dit, il importe de bien comprendre qu'aux yeux de Gandhi et de ses successeurs, Rawls est moins éloignée de la pensée conservatrice qu'il n'y paraît puisque, derrière une défense affichée de la désobéissance civile, sa pensée tend, par des voies indirectes et subtiles, à en restreindre au maximum son usage. Cette méfiance libérale envers la pratique désobéissante ne doit finalement pas nous surprendre car, comme le fait remarquer Yves Sintomer à propos d'Habermas, «à partir du moment où l'accent est mis sur la dynamique normative vertueuse des États démocratiques contemporains », il est logique que la désobéissance civile, toute légitime qu'elle soit, ne puisse exister « qu'à la marge » $(1999$ : 329).

\section{2) La crainte du désordre}


Outre l'occultation des manifestations radicales de la désobéissance civile, la critique désobéissante de l'approche libérale a pour second enjeu la question du désordre. Rawls fait explicitement savoir qu'il pose des conditions de validité à la désobéissance civile pour l'empêcher d'entraîner la société vers l'anomie. Aux yeux de Gandhi, cette crainte est infondée au sens où on ne peut imputer à la désobéissance civile la responsabilité des troubles éventuels qui s'ensuivent.

On pourrait soutenir, en s'appuyant sur la théorie wébérienne des effets pervers13, que les activistes désobéissants, en tentant d'améliorer l'ordre des choses, risquent de précipiter sa ruine. Ce n'est pas le cas, répond Gandhi. La désobéissance civile ne fait que consolider les acquis. Les adversaires politiques de Gandhi ont reproché à la non-coopération d'exciter les masses et d'entraîner des violences. Il est vrai que, malgré l'affichage d'intentions non-violentes, ses campagnes d'agitation publique ont à plusieurs reprises conduit à des émeutes sanglantes 14 . Pourtant, le Mahatma explique de manière assez convaincante que ce n'est pas la non-coopération qui constituait ici un danger pour la démocratie. En effet, la désobéissance civile n'a fait que révéler la violence, latente, qui existait déjà au sein de la société coloniale. Mais elle n'en est pas la cause à proprement parler, puisqu'elle ne fait que ressortir ce qui était déjà présent, de manière sous-jacente. «Le fait que la désobéissance civile se transforme en désobéissance violente n'est pas, je dois l'avouer à regret, une situation improbable. Mais je sais qu'elle n'en sera pas la cause. La violence est déjà là qui corrode tout le monde politique. La désobéissance civile ne sera qu'un processus de purification et fera peut-être remonter à la surface ce qui est enfoui dans ce monde » (Gandhi, 2007 : 346). Les injustices antérieures à la campagne de satyagraha sont la cause réelle des émeutes. Gandhi peut ainsi affirmer, en rigueur de termes, que « la désobéissance civile ne conduit jamais à l'anarchie» (2007 : 269) ni au désordre. Elle ne fait que mettre à jour le désordre sous-jacent au pseudo-ordre établi.

13 Aussi appelée «paradoxe des conséquences », qui soutient que le résultat final d'une action politique est souvent contraire à l'intention originelle ayant présidé à l'action.

14 En février 1919 Gandhi perd le contrôle du mouvement qu'il avait initié contre les lois Rowlatt qui restreignaient considérablement les libertés individuelles. Il s'ensuit des émeutes, des pillages et des vols à travers toute l'Inde. La non-coopération tourne à nouveau à l'émeute en 1921. Gerald Runkle critique Gandhi en disant que si Gandhi n'avait pas anticipé ces répercussions violentes, alors il manquait de prévoyance. Si, au contraire, il s'y attendait, alors il était prêt à accepter les conséquences violentes de l'action non-violente (Runkle, 1976 : 383 ). 
On pourrait aussi soutenir, comme l'a fait le juge américain Francis Ford (de la Cours fédérale de Boston), que de la désobéissance civile à la criminalité il n'y a qu'un pas que les désobéissants auront tôt fait de franchir. Cette intuition est pourtant démentie par les études sociologiques (National Commission on the Causes and the Prevention of Violence, 1969). Hannah Arendt, commentant ces études, en conclut que les preuves qui pourraient démontrer que des actes de désobéissance civile ont tendance à conduire à la criminalité « ne sont pas insuffisantes : elles font totalement défaut» (1972 : 75). Howard Zinn ajoute que le fait de désobéir à la loi dans le cadre de luttes sociales ne mène aucunement ceux qui ont pratiqué la désobéissance civile à enfreindre la loi pour d'autres raisons. Il appuie son propos en renvoyant aux conclusions d'une étude parue dans le International Journal of Social Psychiatry. Cette étude, portant sur trois cents jeunes Afro-américains ayant pratiqué la désobéissance civile, n'a découvert « pratiquement aucune manifestation de comportements délinquants ou antisociaux, pas plus d'ailleurs que de décrochage scolaire ou de grossesses hors mariage ». En conclusion, les auteurs affirment que, « dans tous les cas, on manque de preuves pour affirmer que la désobéissance civile mène inévitablement au moindre respect de la loi ou qu'elle induit un penchant au comportement criminel» (Zinn, 2010 : 213).

La question du désordre constitue probablement un point nodal de la divergence entre les conceptions libérale et désobéissante de la désobéissance civile. Dans la perspective libérale, le désordre résultant des pratiques désobéissantes reste constamment subordonné à la préservation et à la perpétuation de l'ordre démocratique. Il n'est acceptable que s'il contribue à consolider les institutions de l'Etat de droit. Jacques Rancière a sur ce point montré combien la philosophie rawlsienne et celle habermassienne étaient animées par le souci « policier » d'assurer un partage du sensible où chacun serait renvoyé à sa place, à sa fonction, à son rang (1995). Autrement dit, la philosophie libérale promeut in fine une conception ordonnée et ordonnatrice de la démocratie (Vitiello, 2011 : 215). Le conflit n'est accepté provisoirement que dans la mesure où il permet, au final, de «stabiliser les institutions justes ». La pensée désobéissante, à l'inverse, ne craint pas le 
désordre et les conflits qui le suscitent. Elle fait sienne l'idée machiavélienne des Discorsi (1980), magistralement exhumée par Claude Lefort, d'après laquelle le conflit, les tumultes et le désordre sont la source première de la liberté (Lefort, 1972 : 474). Admettre que le conflit, la division sociale et les désordres qui les accompagnent - dont la désobéissance civile est l'une des manifestations exemplaires - constituent le facteur essentiel de la liberté politique conduit logiquement à accorder à la désobéissance une place de premier ordre à la désobéissance dans la dynamique démocratique. Là où, pour les libéraux, la désobéissance était tolérée sous strictes conditions, elle est érigée en élément constitutif de la démocratie par Thoreau, Gandhi et l'ensemble de la pensée désobéissante. On s'aperçoit ainsi finalement que le rapport au conflit et au désordre influe de manière déterminante sur la place que libéraux et désobéissants accordent respectivement à la désobéissance civile.

Le débat entre désobéissants et libéraux gagne alors subitement en profondeur. Il concerne désormais la validité de la thèse désobéissante (empruntée à Machiavel) selon laquelle le conflit serait source de liberté. Bien que tous les penseurs désobéissants mentionnés dans cet article (Thoreau, Gandhi, King, Muller, Zinn) adhèrent à cette thèse, aucun d'eux n'a jamais explicitement entrepris d'en démontrer la validité. Aussi n'est-il pas inutile de prolonger leur travail et de nous atteler à cette démonstration, en nous inspirant de deux penseurs français issus du groupe Socialisme ou Barbarie, Claude Lefort et Cornelius Castoriadis. La consubstantialité du conflit et de la liberté n'est concevable qu'à condition d'adopter une définition adéquate de la liberté, appréhendée ici en tant qu'autonomie, c'est-à-dire, littéralement, en tant que capacité à se donner ses propres lois, de manière lucide et explicite (Castoriadis, 1999). Dès lors, la liberté implique la possibilité permanente de discuter et questionner, en pratique et en théorie, les lois qui régissent la communauté.

Deux voies s'ouvrent alors concernant l'origine de la Loi. Soit celle-ci est renvoyée à un référent transcendant, à une Idée du Bien, à une essence naturelle de l'homme, à la volonté d'un sage législateur, à sa conformité à la Raison universelle. Alors la loi, en tant qu'incarnation de la Justice, 
est incontestable - sauf à vouloir le Mal, ce qu'aucun être raisonnable n'osera défendre. Soit, deuxième possibilité, on assume que la loi est issue d'un rapport de forces qui découle lui-même d'un l'affrontement politique. C'est alors reconnaître qu'elle pourrait être autre puisque, issue d'un conflit politique, elle demeure en partie arbitraire, donc discutable, contestable et modifiable. Dès l'instant où l'homme admet que les lois ne sont pas données mais construites, il est directement amené à concevoir la possibilité de les changer. Si l'on assume que la loi est issue du résultat d'un conflit - et non d'une connaissance du Bien, d'un accord rationnel ou d'un consensus raisonnable sur ce qu'elle doit être, l'issue de ce conflit étant toujours en partie arbitraire, la loi elle-même est marquée de cet arbitraire et reste ainsi légitimement contestable. La conscience du fait que la loi est posée par les hommes alors même que persiste un sérieux désaccord sur son contenu est donc garante de la possibilité qu'ont les hommes de la rediscuter et de continuer ainsi à être auteurs de leurs propres lois. La liberté est donc à la fois condition de possibilité et résultat du conflit. La conscience historique dissout les repères de la certitude et substitue ainsi à la notion d'un pouvoir légitime celle d'un régime fondé sur la légitimité d'un débat sur le légitime et l'illégitime, débat nécessairement sans garant et sans terme (Lefort, 1986 : 59). Seule cette posture antimétaphysique - qui admet que la loi repose sur une construction humaine en partie arbitraire - autorise en retour à se ressaisir de la loi pour la contester si besoin est. Le conflit est donc indissociablement la source et la conséquence de la liberté.

\section{Conclusion : Portée pratique du débat}

L'approche libérale de la désobéissance civile conditionne la légitimité de celle-ci par le respect du principe d'ultime recours (la désobéissance civile n'est légitime que si toutes les voies juridiques ont été essayées et se sont révélées infructueuses), par l'acceptation de la peine (l'activiste désobéissant doit plaider coupable devant le tribunal et accepter de plein gré son incarcération) et par le refus aprioriste et absolu de toute forme de violence. 
Pourtant, l'idée que la désobéissance civile n'est légitime qu'à condition de prendre place après l'échec avéré de tous les moyens légaux de contestation peut être nuancée. Comme l'écrit Pierre-Arnaud Perrouty, cette condition n'est «pas toujours nécessaire. [...] Le déni de justice est parfois si flagrant qu'on n'imagine pas la minorité entamer un long parcours judiciaire avant d'exprimer son refus d'obéir » (2000 : 36). La gravité de la situation fait de la désobéissance civile le seul moyen efficace et rapide de résolution d'un problème. Le cas d'urgence vaut donc légitimation. En outre, les voies de recours légales étant quasiment inépuisables, une désobéissance civile légitime se trouve presque impossible à concrétiser dans la réalité (Bigirimana, $2005: 340$ ).

Le principe d'acceptation de la sanction juridique à lui aussi été fortement critiqué par la pensée désobéissante, en la personne d'Howard Zinn, pour qui cette condition est à la fois incohérente et inefficace. Se soumettre à la sanction trahit l'esprit initial de la désobéissance civile et l'affaiblit. S'il faut parfois accepter la prison par pragmatisme (pour susciter l'indignation de l'opinion publique face à l'incarcération d'un innocent), il n'existe en revanche aucune obligation éthico-politique de se soumettre à la sanction. Une telle acceptation serait incohérente puisque, selon Zinn, lorsque la loi enfreinte est clairement injuste ou inconstitutionnelle, la sanction est aussi injuste que la loi transgressée, de sorte que l'acceptation de la peine est un mensonge moral et juridique (2010 : 197). L'incohérence morale se voit doublée d'une inefficacité stratégique puisque l'acceptation de la sanction encourage l'État à maintenir et à faire respecter la loi ou la politique attaquée. Elle risque aussi d'envoyer un message ambigu à l'opinion publique en lui faisant croire, à tort, que l'on considère que la soumission à la sanction est moralement justifiée.

Enfin, il convient de rappeler que, dans une perspective libérale, les activistes doivent refuser par avance et de manière absolue de pratiquer la moindre forme de violence. Considérant comme excessive cette condition de légitimité de la désobéissance civile, Gandhi refusait pour sa part de faire de la non-violence une «doctrine absolue ». Ainsi affirmait-il que «s'il fallait absolument faire un choix entre la lâcheté et la violence, je conseillerais la violence » (1990:182). Par ce biais, il ouvrait la possibilité d'une distinction entre la violence physique appliquée aux 
personnes et celle appliquée à leurs objets. Peut-on vraiment qualifier de « violentes » les atteintes aux objets et à la propriété privée ? La pensée désobéissante n'apporte ici aucune réponse évidente. De Gandhi à Howard Zinn en passant par Jean-Marie Muller et Martin Luther King, les avis divergent. Mais la pensée désobéissante a le mérite de soulever le problème, contrairement à la philosophie libérale qui disqualifie dès le départ toute forme de violence physique, y compris celle appliquée aux objets.

\section{Bibliographie}

Abensour, Miguel. 2002. « Pour une philosophie politique critique ?». Tumultes. 17/18 : 207-258.

Arendt, Hannah. 1972. Du mensonge à la violence. Paris : Calmann-Lévy.

Audard, Catherine. 2002. "Le principe de légitimité démocratique et le débat Rawls-Habermas ». Dans Habermas, l'usage public de la raison, dir. Rainer Rochlitz. Paris : PUF. 95-132.

Bedau, Hugo Adam. 1991. «Civil Disobedience and Personal Responsability for Injustice ». Civil Disobedience in Focus, dir. Hugo Adam Bedau. Londres : Routledge.

Bigirimana, Consolate. 2005. «Essai d'analyse philosophique de la désobéissance civile ». Laval théologique et philosophique. 61/2:337-344.

Blanchard, Martin, dir. 2012. Dossier « Violence et démocratie délibérative ». Ateliers de l'éthique. 7/1:45-140

Bobbio, Norberto. 1999. «La resistenza all'oppressione oggi». Dans Teoria generale della politica. Roma : Biblioteca Einaudi. 199-213.

Boltanski, Luc, Bourdieu, Pierre. 2008. La production de l'idéologie dominante. Paris : Raisons d'Agir.

Castoriadis, Cornelius. 1999. L'institution imaginaire de la société. Paris : Seuil.

Cavell, Stanley. 2009. Qu'est-ce que la philosophie américaine : de Wittgenstein à Emerson. Paris : Gallimard.

Cervera-Marzal, Manuel. 2012a. «Prolonger Abensour. La désobéissance civile comme modalité de l'utopie ». Variations. $16: 114-138$

Cervera-Marzal, Manuel. 2012b. «Gandhi : de l'antilibéralisme à l'anarchisme non-violent». Réfractions. 28 : 125-141.

Di Cintio, Chloé. 2010. Petit traité de désobéissance civile. Paris : Respublica.

Dworkin, Ronald. Ronald. 1996. «Désobéissance civile et protestation contre le nucléaire ». Dans Une question de principe. Paris : PUF. 133-150.

Falcon y Tella, Maria José. 2003. «Un droit à la désobéissance civile ». Dans Vers une culture des droits de l'homme. Genève : Editions Diversités. 128-150

Ferrarese, Estelle. 2010. «Le conflit politique selon Habermas ». Multitudes. 41 : 196-202.

Fortas, Abe. 1968. Concerning Dissent and Civil Disobedience. New York : Signet.

Fung, Archon. 2011. « Délibérer avant la révolution ». Participations 1 : 311-334.

Gandhi, Mohandas K. 1990. Tous les hommes sont frères. Paris : Gallimard.

Gandhi, Mohandas K. 2007. Résistance non-violente. Paris : Buchet/Chastel.

Habermas, Hans. 1990. « Le droit et la force ». Dans Ecrits politiques. Paris : Cerf.

Habermas, Hans. 1997. Droit et Démocratie, entre faits et normes. Paris : Fayard.

Habermas, Hans. 1998. L'intégration républicaine. Paris : Fayard.

Habermas, Hans. 2003. « De la tolérance religieuse aux droits culturels ». Cités. 13 : 151-170.

Habermas, Hans, Rawls, John. 1997. Débat sur la justice politique. Paris : Cerf. 
Haksar, Vinit. 2003. "The Right to Civil Disobedience ». Osgoode Hall Law Journal. 41/2 : 408419.

Laugier, Sandra. 2004. Une autre pensée politique américaine : La démocratie radicale d'Emerson à Stanley Cavell. Paris : Michel Houdiard Editeur.

Lefort, Claude. 1972. Le travail de l'œuvre. Machiavel. Paris : Gallimard.

Lefort, Claude. 1986. Essais sur le politique. Paris : Seuil.

Legros, Robert. Goethe : "Je préfère commettre une injustice que de tolérer un désordre ", disponible sur http://www.philomag.com/article,phrasechoc,goethe-je-prefere-commettre-uneinjustice-que-de-tolerer-un-desordre,461.php (consulté le 6 février 2012)

Lemasson, Laurent. 2008. "La démocratie radicale de Jürgen Habermas. Entre socialisme et anarchie ». Revue Française de Science Politique. 58 : 39-67

Machiavel, Nicolas. 1980. Discours sur la première décade de Tite-Live. Paris : Berger-Levrault.

McNay, Loic. 2008. "Recognition as Fact and Norm : the Method of Critique ». Dans Political theory: methods and approaches, ,dir. David Leopold et Marc Stears, New York : Oxford University Press. 85-105

Mellon, Christian. 1998. "Qu'est-ce que la désobéissance civile?». Dans Alternatives Nonviolentes. 108.

Moreall, John. 1976. «The Justifiability of Violent Civil Disobedience ». Canadian Journal of Philosophy. $6: 35-44$.

Muller, Jean-Marie. 1981. Stratégie de l'action non-violente. Paris : Seuil.

Muller, Jean-Marie. 1994. Gandhi, la sagesse de la non-violence. Paris : Desclée de Brouwer.

Muller, Jean-Marie. 1997. Gandhi l'insurgé, L'épopée de la marche sur sel. Paris : Albin Michel.

Muller, Jean-Marie. 2007. «Vous avez dit « désobéisseur»? ». Dans Alternatives Non-violentes. 142.

National Commission on the Causes and the Prevention of Violence. 1969. «To Establish Justice, to Insure Domestic Tranquility ».

Neal, Patrick. 2001. «Theory, Postwar Anglo-American». Da,s Political philosophy: theories, thinkers, and concepts, dir. Seymour Lipset. Washington : CQ Press.

Pantham, Thomas. 1983. «Thinking with Mahatma Gandhi: Beyond liberal democracy ». Political Theory. 11/2:165-188.

Perrouty, Pierre-Arnaud. 2000. «Légitimité du droit et désobéissance ». Dans Obéir et désobéir, Le citoyen face à la loi, dir. Pierre-Arnaud Perrouty. Bruxelles : Editions de l'Université de Bruxelles.

Power, Paul. 1970. «On Civil Disobedience in Recent American Democratic Thought». The American Political Science Review. 64/1 : 35-47

Quelquejeu, Bernard. 1998. «Comment John Rawls justifie-t-il la désobéissance civile ?». Dans Alternatives Non-violentes. $108: 5-14$

Rancière, Jacques. 1995. La mésentente : politique et philosophie. Paris : Galilée.

Rawls, John. 1987. Théorie de la Justice. Paris : Seuil.

Refalo, Alain. 2005. "La criminalisation de la désobéissance civile». Dans S!lence. 329. Disponible sur http://www.non-violence-mp.org/reflexions_fichiers/refalo2.htm (consulté le 6 février 2012)

Runkle, Gerald. 1976. « Is Violence Always Wrong ?». The Journal of Politics, 38/2 : 367-389.

Sintomer, Yves. 1999. La démocratie impossible ? Politique et modernité chez Weber et Habermas. Paris : La Découverte.

Thoreau, Henry David. 1994. Désobéir. Paris : Editions de l'Herne.

Venner, Fiammeta. 1995. L'opposition à l'avortement, du lobby au commando. Paris : Berg International.

Vitiello, Audric. 2011. « La démocratie agonistique ». Revue du MAUSS. 38/2 : 213-234.

Zinn, Howard. 2010. Désobéissance civile et démocratie. Marseille : Agone. 